\title{
Budbreak Number in Apple Seedlings as Selection Criterion for Improved Adaptability to Mild Winter Climates
}

Iwan F. Labuschagné ${ }^{1}$, J.H. Louw ${ }^{2}$, Karin Schmidt, and Annalene Sadie ${ }^{3}$ South African Agricultural Research Council, Fruit, Vine, and Wine Research Institute, Private Bag X5013, Stellenbosch, 7599, Western Cape, South Africa

Additional index words. Malus $\times$ domestica, fruit breeding, heritability, climatic adaptation, selection response

\begin{abstract}
Absence or long delay of budbreak, also known as prolonged dormancy, is the most important symptom during incomplete dormancy. Budbreak number was evaluated to quantify seedling response to chilling and selection on excised and intact 1-year-old apple (Malus $\times$ domestica Borkh.) seedlings under controlled and natural environmental conditions. Indices based on: 1) the number and distribution of budbreak (prolonged dormancy grade = PDG); 2) the number of buds breaking, including shoot length with increased budbreak as part of the calculation (prolonged dormancy index = PDI); and 3) budbreak number per $100-\mathrm{cm}$ shoot $(\mathrm{NB})$ were tested in association with budbreak time (TB). The indices expressed the effects of cold treatments that induce earlier and higher numbers of budbreak. PDI and NB, but not PDG, identified families with increased budbreak. Seedlings with high PDG and NB were also associated with families in which high chill requiring parents were used, indicating that $\mathrm{TB}$ as pre-selection criterion may fail to identify seedlings with increased budbreak. Response to pre-selection for increased budbreak using PDG could be verified with the PDS and NB indices in seedlings and seedling clones. The NB of intact 1-year-old shoots under natural conditions is recommended as a pre-selection criterion against prolonged dormancy in suboptimal winter conditions.
\end{abstract}

Deciduous fruit trees must undergo periods of low temperature to satisfy the rest or chilling requirement (CR). If chilling is insufficient, $a b-$ normal and undesirable growth characteristics, such as reduced budbreak, can occur. This is a common phenomenon on temperate trees being cultivated under mild winter climates, such as those prevailent in the Western Cape of South Africa (Cook and Jacobs, 2000).

$\mathrm{CR}$ is a genetically complex trait (Dennis, 1987; Howe et al., 1999) and quantitative or semi-quantitative measurements on a number of related qualities have been proposed to estimate CR. Quantitative models related to bud dormancy involve the use of chill unit (CU) accumulation to describe the phenological events and the determination of endpoints of dormancy (Allan et al., 1993; Fuchigami and Wisniewski, 1997; Linsley-Noakes et al., 1995; Mauget and Rageau, 1988). CR measurement is frequently based on bud development traits,

Received for publication 4 Aug. 2002. Accepted for publication 4 Feb. 2003. This study was funded by the South African Fruit Producers Trust. The paper was submitted by the senior author in partial fulfillment of the requirements for a $\mathrm{PhD}$ degree in genetics. ${ }^{1}$ To whom reprint requests should be addressed. Fax: + 272187 42006; e-mail: iwan@infruit.agric.za

${ }^{2}$ Senior Lecturer in Genetics, Faculty of Agriculture and Forestry Sciences, Dept. of Genetics, Stellenbosch Univ., Matieland, 7602, Western Cape, South Africa.

${ }^{3}$ Lecturer in Biometry, Faculty of Agriculture and Forestry Sciences, Dept. of Genetics, Stellenbosch Univ., Matieland, 7602, Western Cape, South Africa. such as budbreak time, rate, number, or percentage of budbreak (Bradshaw and Stettler, 1995; Chandler, 1960; Hauagge and Cummins, 1991a; Herter et al., 1988).

Predictions of the timing of various phenological events using models, e.g., budbreak at specified intervals on excised 1 -year-old shoots under forced conditions, have also been used (Cook and Jacobs, 2000; Halgryn et al., 2001; Linsley-Noakes et al., 1995). Early-breaking genotypes, such as the apple cultivar Anna, have low CR and are expected to be more widely adaptable (Chandler, 1960; Hauagge and Cummins, 1991a). Indeed, 'Anna' was selected because of its early leafing trait (Oppenheimer and Slor, 1968).

Budbreak is probably more prolific (higher budbreak number), and occurs promptly and uniformly in low CR genotypes (Chandler, 1960; Hauagge and Cummins, 1991a). Adaptability grades, i.e., degrees of adaptability of apple seedlings have then been defined according to the number of lateral buds that break and the uniformity of the budbreak (Hauagge and Cummins, 1991b). In another case, apples were classified on a scale from 1 (no lateral buds breaking) to 10 (100\% buds breaking) (Denardi et al., 1988).

Against this background of varying approaches to the CR quantification problem we report the results of five separate experiments performed from 1995 to 2000 . The experiments were performed under controlled and natural conditions, and included different materials. Some aspects of seedling budbreak as a measure of CR, and possible criterion of selection for improved adaptation to local conditions were investigated. The main aspects covered in these experiments are: 1 ) the response to chilling; 2) variation between and within families of crosses; and 3) responses to selection.

\section{Materials and Methods}

\section{Controlled environmental conditions}

Experiment 1. One hundred 3-year-old seedlings from each of four families ('Starking Delicious' $x$ '2B-18-67', 'American Seedling' x 'Royal Gala', 'Starking Delicious' $x$ '2A16-15', and 'Braeburn' $\mathrm{X}$ '2B-26-59') were transferred to a cold room $\left(4 \pm 2{ }^{\circ} \mathrm{C}\right)$ after leaf fall. Seedlings received cold treatment corresponding to $800,1000,1200,1400$, and 1600 CU. Cold units were calculated according to the modified Utah equation (Richardson et al., 1974), which was regarded more suitable for local chilling conditions where negative CU values are not carried from one day to the next (Linsley-Noakes et al., 1995). Samples of 20 seedlings per family were randomly positioned in two replications in a growth chamber $(20$ $\pm 2{ }^{\circ} \mathrm{C}$ ) to induce budbreak. Twenty-one days after the initial budbreak, seedlings were graded from 0 to 5 for PDG as judged from the number and distribution of vegetative buds breaking. Grades ranged from 0 (no budbreak) to 5 (high number of buds breaking), adopted from Hauagge and Cummins, 1991b. The number of days before terminal budbreak for each seedling and the number of days to $50 \%$ budbreak for each family were recorded, following the example of Hauagge and Cummins (1991a).

Experiment 2. One-year-old excised shoots, $\approx 30 \mathrm{~cm}$ long, were sampled from four families derived from crosses with 'Golden Delicious' as the common seed parent and 'Prima', 'Summerking', 'Starking Delicious', and 'Braeburn' as pollen parents. Shoots were sampled from trees at 2 and 3 years of age growing in randomized blocks. Orchard management was typical of commercial practice except that no pruning or other tree growth manipulations, such as rest-breaking treatment, were applied. Shoots were transferred to a cold room $\left(4 \pm 2{ }^{\circ} \mathrm{C}\right)$ and then to a growth chamber $\left(25 \pm 2{ }^{\circ} \mathrm{C}\right)$ during the end of the growing season at six sampling dates corresponding to cold accumulation units 610, 800, 1020, 1200, 1400, and $1600 \mathrm{CU}$. Twenty shoots from each family were randomly positioned in 5-L plastic containers with $1 \mathrm{~L}$ water and $5 \mathrm{~mL}$ commercial bleach. NB was calculated for each shoot as the number of buds breaking per $100 \mathrm{~cm}$ of shoot.

\section{Natural environmental conditions}

Experiment 3. Controlled hand-crosses involving 10 apple cultivars resulted in 11 families with either 'Royal Gala' or 'Anna' as a parent. The average family size ranged from 140 to 333 seedlings. Data were recorded on 2-year-old seedlings grown under low chill winter conditions of $737 \mathrm{CU}$. The TB (recorded from Jan. 1) of each seedling and the PDG was recorded $21 \mathrm{~d}$ after $50 \%$ of each family reached budbreak. Two-way mass selection for high and low number of buds breaking 
Fig. 1 (right). Prolonged dormancy symptoms on apple (Malus $\times$ domestica Borkh.) shoots measured according to a prolonged dormancy index (PDI) based on the number of buds broken per shoot, shoot length and distribution of budbreak. Index values were calculated by dividing the measured length of shoot where concentrated budbreak occurred $(C)$, by the total length of shoot $(L)$ and multiplied by the number of buds broken $(N)$ for each seedling $(P D I=C / L \times N)$.

was performed late during the growing season on each family. After selection, NB and PDI, where shoot length with increased budbreak was considered part of the calculation of the index value, were calculated (Fig. 1).

Experiment 4. TB and NB were recorded on 1-year-old intact shoots from 10 open pollinated crosses (77-315 seedlings per family) over 3 years. Seedling growth was revived by cutting back shoots each year. Seedlings received 846,878 , and $708 \mathrm{CU}$ during separate years. During the last two seasons, families were divided into two experimental groups, one subjected to a cold treatment $(+1400 \mathrm{CU})$ and the other to prevailing sub-optimal winter conditions.

Experiment 5. Seedlings, 400 of each of four families ('Braeburn' $x$ 'Golden Delicious'; 'Golden Delicious' $x$ 'Royal Gala'; 'Royal Gala' x 'Braeburn' and 'Mollies Delicious' open pollinated), were divided into two groups. During the first season, half of each family received a cold treatment of $1400 \mathrm{CU}$ and the other half was subjected to prevailing suboptimal winter temperatures $(730 \mathrm{CU})$. Seedlings were planted in randomized blocks in a nursery. TB and NB were recorded on each seedling where standard nursery practices were applied with no pruning and rest breaking treatments.

During the following season, two-way selection for high and low budbreak number (50 in each selection group) was applied based on NB. After selection, half of each group (25 seedlings) received a cold treatment and the other half were exposed to suboptimal winter chilling conditions of $846 \mathrm{CU}$. TB and NB were recorded. Afterwards, 50 seedlings from each of the selection groups were cloned by budding on M25. One tree from each combination received $1600 \mathrm{CU}$ and the other 708 CU. TB and NB were recorded.

Data analysis. We adopted the experimental procedure of controlled two-way truncation selection for high and low budbreak number, providing the best possible experimental control for the measurement of response to selection (Falconer and Mackay, 1996). Linear regression analyses were performed using SAS Proc. Reg. procedure and analyses of variance (ANOVA) were carried out using SAS General

Fig. 2 (right). Changes in (A) prolonged dormancy grades (PDG), (B) number of days at $20{ }^{\circ} \mathrm{C}$ to terminal budbreak, and (C) days to $50 \%$ family budbreak of 3-year-old apple (Malus $\times$ domestica Borkh.) seedlings from four families forced in a controlled environment $\left(20 \pm 2^{\circ} \mathrm{C}\right)$. Lines represent regression of criteria means on cold unit (CU) accumulation.

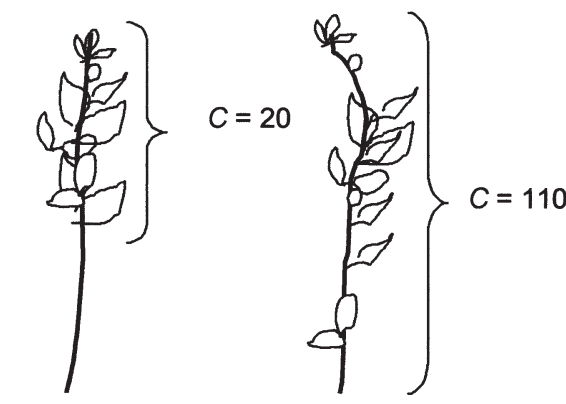

$L=120$

$N=9$

$\mathrm{PDI}=1.5$

$L=120$

$N=9$

$\mathrm{PDI}=8.3$

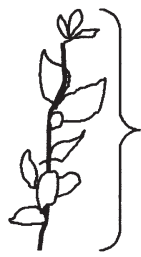

$C=50$

$L=120$

$N=9$

$\mathrm{PDI}=7.5$

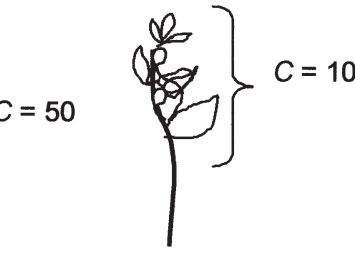

$L=60$

$N=5$

$\mathrm{PDI}=0.8$

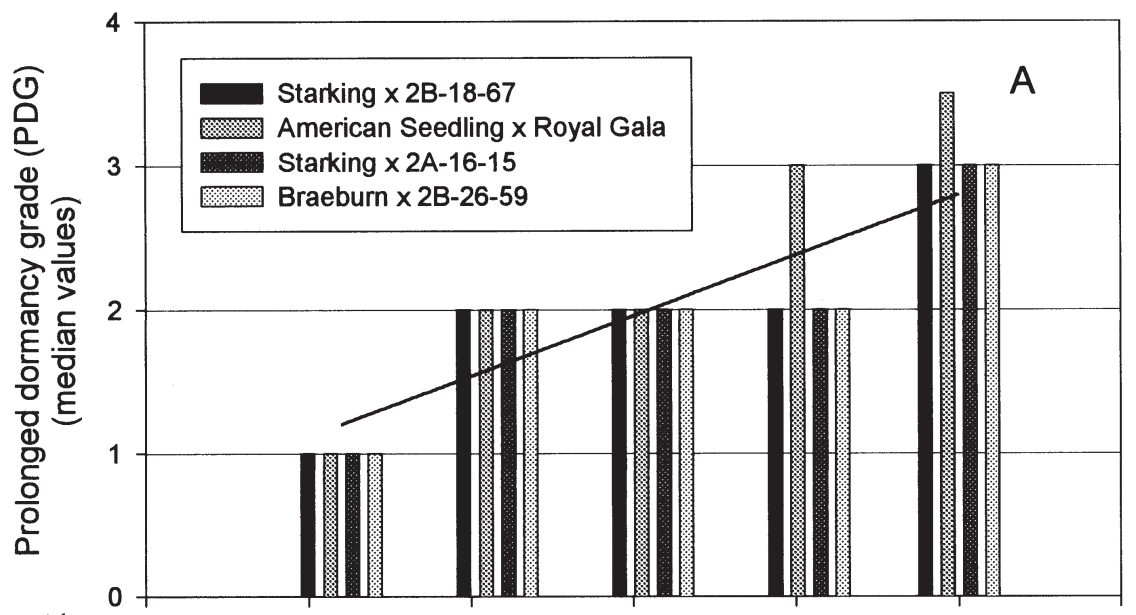

징$$
20
$$
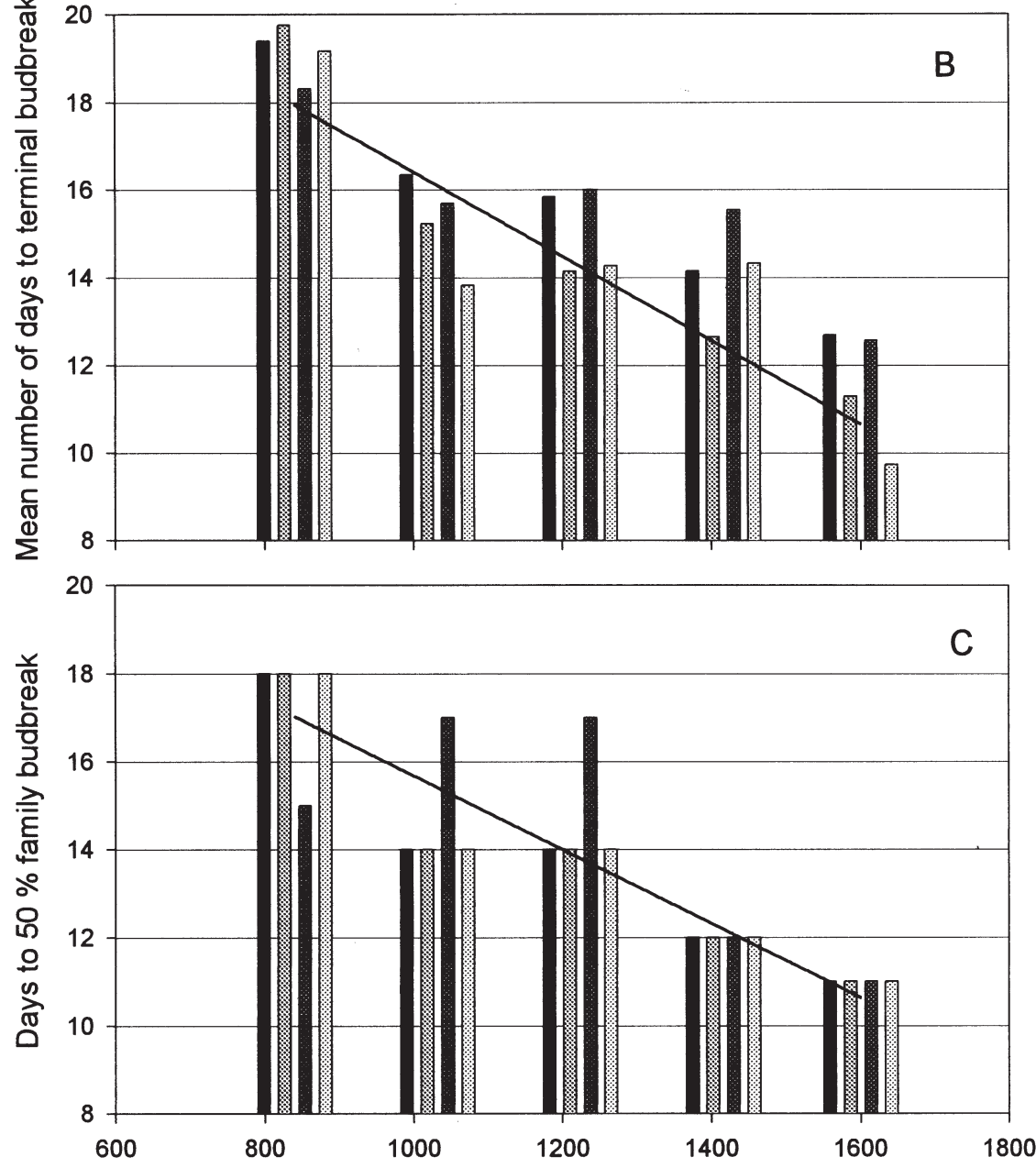
Breeding, Cultivars, Rootstocks, \& Germplasm Resources

Linear Model procedures (SAS Institute, Cary, N.C., 1996) after testing for heterogeneity of variance by means of the Levene test (Snedecor and Cochran, 1991) and the Shapiro-Wilk test for normality (Shapiro and Wilk, 1965). Data sets were weighted for homogeneity of variance and transformed to reduce deviations from the normal distribution where necessary. Multiple comparisons were performed using Fisher's and Student's $t$ LSD tests. Correlation analyses were performed using the SAS Correlation procedure.

\section{Results}

\section{Controlled environmental conditions}

Experiment 1. A separate regression line was fitted for each of the four families and the slopes of these lines were compared using Fisher's LSD test. Based on PDG medians and with respect to the average regression $\left(\mathrm{R}^{2}=\right.$ 0.893), seedlings showed increased budbreak during cold accumulation (Fig. 2A). The slopes of 'American Seedling' $x$ 'Royal Gala' differed significantly $(P=0.05)$ from 'Braeburn' $\times 2 \mathrm{~B}$ 26-59. Number of days at $20^{\circ} \mathrm{C}$ before terminal budbreak decreased during $\mathrm{CU}$ accumulation $\left(\mathrm{R}^{2}=0.866\right)$ (Fig. 2B). ANOVA of days at $20{ }^{\circ} \mathrm{C}$ before terminal budbreak indicated no significant differences between families. The number of days to $50 \%$ budbreak in all families decreased with cold accumulation $\left(\mathrm{R}^{2}=0.944\right)$ (Fig. 2C). The family 'Starking' $x$ '2A-16-15' indicated a more delayed budbreak at higher chilling conditions compared to other families. PDG and days at $20^{\circ} \mathrm{C}$ before budbreak were negatively associated for all sampling dates $\left(\mathrm{R}^{2}=0.517\right)$.

Experiment 2. Regression analysis of $\mathrm{NB}$ on $\mathrm{CU}$ for each family over 2 years indicated significant association for year two only $\left(\mathrm{R}^{2}\right.$ $\approx 0.25$ ) and that a nonsignificant percentage of the variance in $\mathrm{NB}$ is accountable to $\mathrm{CU}$ in this trial. A joint analysis of heterogeneity of regression by ANOCOVA (Covariance analysis) for $\mathrm{NB}$ on $\mathrm{CU}$ over families showed no differences between families $(P=0.1106)$. A positive response of budbreak on $\mathrm{CU}$ during the second year indicates that experimental or sampling errors may have been involved during the first year's trial or that the juvenile phase of seedlings may have shifted from the first to the second year.

\section{Natural environment}

Experiment 3. Median values for PDG did not differ between families. The percentage of seedlings per family with high PDG ranged from $6.7 \%$ to $20.7 \%$ (Table 1). Seedlings with high PDG (4 and 5) from high CR parents comprised $12.8 \%$ of all seedlings, and $10.3 \%$ from the low CR parent and all seedlings with grades 4 and 5 showed budbreak within $21 \mathrm{~d}$ of $50 \%$ family budbreak. In families where 'Anna' was a parent, early budbreak occurred after 737 CU. The date on which the first family, namely 'Royal Gala' X 'Anna', reached 50\% budbreak (the "initial budbreak" used as reference point for other families) was mid-August. The last

Table 1. Mean apple (Malus $\times$ domestica Borkh.) family budbreak time as $50 \%$ budbreak in days after initial budbreak and percentage of seedlings within high prolonged dormancy grades (PDG) before two-way selection was applied according to the prolonged dormancy index (PDI).

\begin{tabular}{lccc}
\hline Family & $\begin{array}{c}\text { No. of } \\
\text { seedlings }\end{array}$ & $\begin{array}{c}\text { Days to 50\% after } \\
\text { initial budbreak }\end{array}$ & $\begin{array}{c}\text { \% Seedlings in } \\
\text { PDG 4 and 5 }\end{array}$ \\
\hline Royal Gala X Annay $^{z}$ & 233 & 5.6 & 14.0 \\
Braeburn X Anna $^{y}$ & 167 & $0.0^{x}$ & 6.7 \\
Braeburn X Royal Gala & 174 & 17.0 & 6.7 \\
Royal Gala x Priscilla & 327 & 25.5 & 12.0 \\
Royal Gala x Braeburn & 325 & 24.6 & 6.6 \\
Royal Gala x Full Red & 311 & 31.7 & 14.0 \\
Royal Gala X Red Chief & 288 & 30.4 & 14.8 \\
Royal Gala X Fuji & 140 & 19.6 & 20.7 \\
Royal Gala X Fiesta & 230 & 28.9 & 19.5 \\
Royal Gala x Lady Williams & 333 & 35.5 & 13.4 \\
Royal Gala x Jona Red & 167 & 31.0 & 9.7 \\
\hline
\end{tabular}

${ }^{2}$ PDG 4 and 5 refer to seedlings identified visually with high numbers and even distribution of budbreak.

y'Anna' has one of the lowest chilling requirements found in Malus $\times$ domestica Borkh. (Brooks and Olmo, 1972).

'Initial budbreak of 'Braeburn' $x$ 'Anna' used as reference for budbreak time in other families.

Table 2. Mean prolonged dormancy index (PDI) and budbreak number (NB) calculated for apple (Malus $\times$ domestica Borkh.) seedling families after selection based on prolonged dormancy grades (PDG). Correlation coefficients indicate association between PDI and NB based on covariance analysis.

\begin{tabular}{|c|c|c|c|c|c|c|c|c|}
\hline \multirow[b]{2}{*}{ Family } & \multicolumn{2}{|c|}{ No. selected } & \multicolumn{2}{|c|}{ Mean PDI } & \multicolumn{2}{|c|}{ Mean NB } & \multicolumn{2}{|c|}{$r$} \\
\hline & High & Low & High & Low & High & Low & High & Low \\
\hline Royal Gala X Anna & 41 & 43 & 10.86 & 0.55 & 17.47 & 4.95 & 0.75 & 0.78 \\
\hline Braeburn $x$ Anna & 30 & 31 & 5.59 & 0.42 & 22.56 & 10.14 & 0.62 & 0.63 \\
\hline Braeburn x Royal Gala & 31 & 32 & 8.53 & 0.12 & 19.78 & 4.22 & 0.38 & 0.57 \\
\hline Royal Gala $\times$ Priscilla & 59 & 59 & 6.81 & 0.03 & 18.82 & 3.16 & 0.84 & 0.58 \\
\hline Royal Gala x Braeburn & 61 & 61 & 8.33 & 0.59 & 15.99 & 3.74 & 0.89 & 0.63 \\
\hline Royal Gala x Full Red & 56 & 59 & 6.09 & 0.01 & 18.80 & 3.16 & 0.60 & 0.16 \\
\hline Royal Gala x Red Chief & 54 & 53 & 7.38 & 0.13 & 17.09 & 2.60 & 0.83 & 0.59 \\
\hline Royal Gala x Fuji & 27 & 28 & 4.10 & 0.80 & 15.75 & 5.10 & 0.70 & 0.63 \\
\hline Royal Gala $\times$ Fiesta & 42 & 42 & 6.02 & 0.29 & 13.30 & 3.06 & 0.79 & 0.84 \\
\hline Royal Gala x Lady Williams & 63 & 63 & 5.34 & 0.09 & 13.78 & 2.97 & 0.74 & 0.67 \\
\hline Royal Gala x Jona Red & 31 & 30 & 5.57 & 0.01 & 14.32 & 2.60 & 0.56 & 0.87 \\
\hline Mean & & & 6.78 & 0.28 & 17.06 & 4.15 & 0.70 & 0.63 \\
\hline
\end{tabular}

Table 3. Mean budbreak time (TB) (recorded from 1 Jan.) and budbreak number (NB) on intact 1-year-old apple (Malus $\times$ domestica Borkh.) seedling shoots after exposure to chilling conditions $(+1400 \mathrm{CU})$ and suboptimal winter conditions $( \pm 800 \mathrm{CU})$ as control. Data were collected over a 2-year period for chill treatment and over 3 years for the control.

\begin{tabular}{llllll}
\hline Family & \multicolumn{2}{c}{ TB } & & \multicolumn{2}{c}{ NB } \\
\cline { 2 - 3 } \cline { 5 - 6 } (open pollinated) & Chill $^{\mathrm{z}}$ & Control $^{\mathrm{z}}$ & & Chill & Control $^{\mathrm{z}}$ \\
\hline Golden Delicious & $279 \mathrm{ab}$ & $301 \mathrm{ab}$ & & $16.30 \mathrm{~d}$ & $10.14 \mathrm{~b}$ \\
Granny Smith & $270 \mathrm{bcd}$ & $292 \mathrm{~b}$ & & $15.43 \mathrm{~d}$ & $10.25 \mathrm{~b}$ \\
Michal & $267 \mathrm{~cd}$ & $261 \mathrm{c}$ & & $16.20 \mathrm{~d}$ & $10.35 \mathrm{~b}$ \\
Sweet Cornelly & $232 \mathrm{f}$ & $260 \mathrm{c}$ & & $17.67 \mathrm{~cd}$ & $10.78 \mathrm{~b}$ \\
Dorsett Golden & $287 \mathrm{a}$ & $305 \mathrm{a}$ & & $15.54 \mathrm{~d}$ & $11.71 \mathrm{~b}$ \\
Braeburn & $275 \mathrm{bc}$ & $294 \mathrm{~b}$ & & $21.38 \mathrm{~b}$ & $13.29 \mathrm{ab}$ \\
Anna & $258 \mathrm{e}$ & $236 \mathrm{~d}$ & & $22.99 \mathrm{ab}$ & $16.16 \mathrm{a}$ \\
Austin & $270 \mathrm{bcd}$ & $267 \mathrm{c}$ & & $22.28 \mathrm{ab}$ & $16.82 \mathrm{a}$ \\
Early O'Henimuri & $266 \mathrm{de}$ & $263 \mathrm{c}$ & & $20.43 \mathrm{bc}$ & $16.95 \mathrm{a}$ \\
Vista Bella & $278 \mathrm{~b}$ & $294 \mathrm{~b}$ & & $24.86 \mathrm{a}$ & $17.63 \mathrm{a}$ \\
\hline
\end{tabular}

${ }^{\mathrm{z}}$ Year $\times$ family interaction used as error term in analysis of variance (ANOVA).

ANOVA performed for each treatment separately.

Different letters indicate significant difference $(P \leq 0.05)$.

families reached $50 \%$ budbreak $35 \mathrm{~d}$ after the initial budbreak date (Table 1), with a time range of $59 \mathrm{~d}$ between the first and the last seedlings. Significant differences of PDI values were detected between families for both high and low groups $(P<0.01)$ (Table 2). Mean PDI values for the high group differed significantly from the low group. Average correlation over families for PDI and NB based on covariance analysis was significant for both groups $(r=$
0.728 and $r=0.612$ ) (Table 2).

Experiment 4. Differences among families from open pollinated seed indicate significant genetic variance for TB and NB on exposure to the cold treatment $(P<0.01)$ and to suboptimal temperatures $(P<0.01)$ (Table 3$)$. Open-pollinated families with lower NB exposed to chilling also showed low mean NB under suboptimal temperatures, i.e., 'Golden Delicious', 'Granny Smith' and 'Michal', 'Austin', 
Table 4. Apple (Malus $\times$ domestica Borkh.) family response to cold treatment measured as NB. Chilling of $1400 \mathrm{CU}$ was applied on one experimental group and the second group was subjected to prevailing suboptimal winter temperatures (control).

\begin{tabular}{|c|c|c|c|c|c|c|c|}
\hline \multirow[b]{2}{*}{ Family } & \multicolumn{2}{|c|}{$\begin{array}{c}\text { Seedlings } \\
\text { before selection }\end{array}$} & \multicolumn{2}{|c|}{$\begin{array}{c}\text { Seedlings } \\
\text { after selection }\end{array}$} & \multicolumn{2}{|c|}{$\begin{array}{c}\text { Clones } \\
\text { after selection }\end{array}$} & \multirow[b]{2}{*}{ Mean } \\
\hline & Chill & $\overline{\text { Control }}$ & Chill & Control & Chill & Control & \\
\hline Braeburn x Golden Delicious & $33.03 \mathrm{a}$ & $22.11 \mathrm{~b}$ & $22.34 \mathrm{a}$ & $13.02 \mathrm{ab}$ & $9.77 \mathrm{a}$ & $5.53 \mathrm{a}$ & 17.63 \\
\hline Golden Delicious x Royal Gala & $26.94 \mathrm{c}$ & $18.01 \mathrm{c}$ & $16.52 \mathrm{~b}$ & $8.89 \mathrm{c}$ & $8.61 \mathrm{~b}$ & $4.39 \mathrm{~b}$ & 13.98 \\
\hline Mollie's Delicious ${ }^{z}$ & $32.05 \mathrm{a}$ & $28.82 \mathrm{a}$ & $26.90 \mathrm{a}$ & $15.78 \mathrm{a}$ & $8.42 \mathrm{~b}$ & $5.24 \mathrm{a}$ & 19.54 \\
\hline Royal Gala x Braeburn & $29.19 \mathrm{~b}$ & $19.62 \mathrm{~b}$ & $18.21 \mathrm{~b}$ & $10.57 \mathrm{bc}$ & $6.93 \mathrm{~b}$ & $5.01 \mathrm{a}$ & 14.92 \\
\hline Mean & 30.30 & 22.14 & 20.99 & 12.07 & 8.43 & 5.04 & \\
\hline
\end{tabular}

${ }^{\mathrm{z}}$ Open pollinated family

Different letters indicate significant difference $(P \leq 0.05)$.

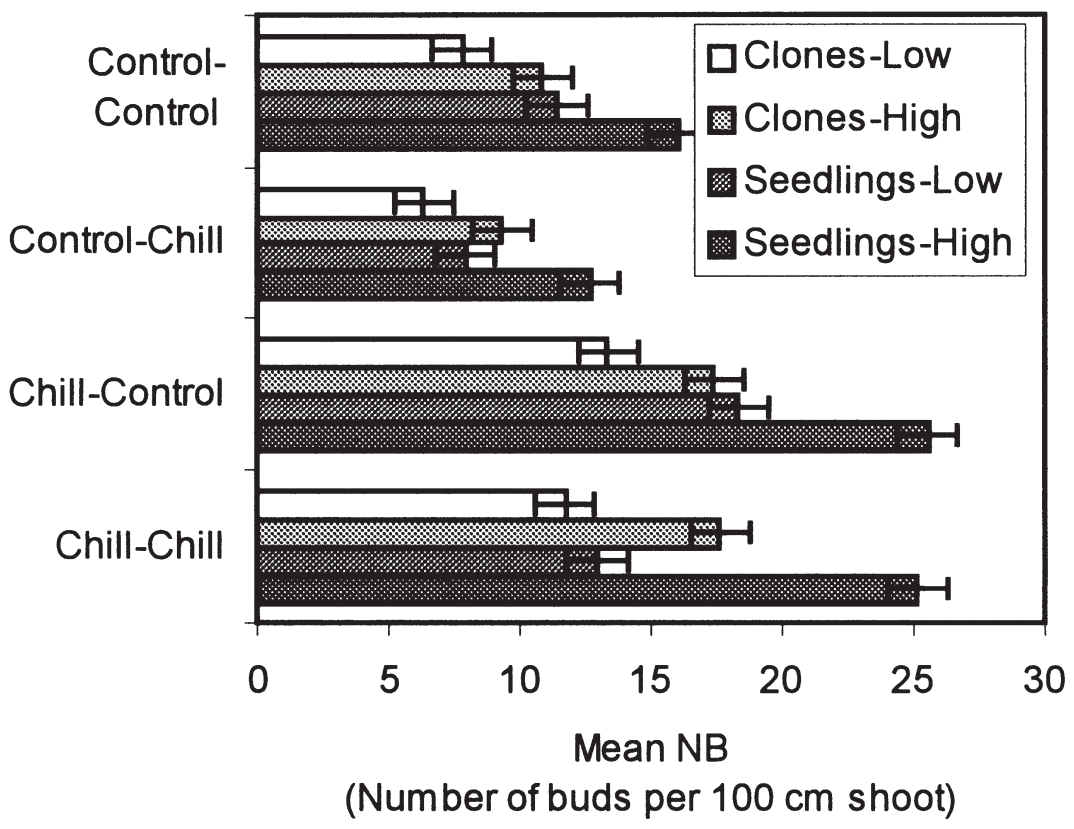

Fig. 3. Budbreak number (NB) averaged over apple (Malus $\times$ domestica Borkh.) families for high and low selections and for different induced chill and control treatment combinations (see text, Expt. 5). Standard error $=1.14$ calculated from ANOVA.

'Early O'Henimuri', and 'Vista Bella' families with high mean NB when exposed to chilling, showed high values under unfavorable conditions. Families with early budbreak did not show high NB. TB was earlier when cold treatment was applied to seedlings (average difference of $16 \mathrm{~d}$ ) and cold treatment induced budbreak in seedlings. ANOVA and ANOCOVAon family means indicate significant genetic variance $(P<0.01)$ and negative genetic covariance $(P<0.01)$ between TB and NB.

Experiment 5. Cold treatment induced budbreak $(37 \%)$ compared to the untreated controls in the first test period. Significant heterogeneity was found among families for NB (Table 4). The higher budbreak number and heterogeneity among families carried over to the second period of testing after selection and also to the cloned seedlings. The initial chill treatment of seedlings was most effective in stimulating $\mathrm{NB}$ and resulted in significantly higher response to selection in both seedlings and clones (Fig. 3). Cold treatment induced earlierTB (10-15 d) compared to the untreated controls. Heterogeneity among families was significant in most cases according to ANOVA (data not shown).

\section{Discussion}

Family differences in the controlled environment where chilling could be systematically increased were evident for PDG and the number of days to $50 \%$ family budbreak, but not for number of days at $20{ }^{\circ} \mathrm{C}$ (Expt. 1). Family differences in the NB were shown in excised shoots in the second year of evaluation only (Expt. 2). Under the natural conditions, family variation for budbreak time was evident, but family differences in PDG could not be shown (Expt. 3). Differences in PDS and NB successfully identified families with increased budbreak (Expts. 3, 4, and 5) and selection groups (Expts. 3 and 5), and family differences for these indices were repeatable over years. In Expt. 5, ANOVA identified variation in NB values between seedling families over a period of 3 years in the young seedlings and seedling clones, and families with increased budbreak showed fairly consistent values over the different treatments using NB.

The high correlation between PDS and NB (Expt. 3) showed that both can distinguish between seedlings for budbreak number but, because PDS (Expts. 1 and 3 ) is more laborious and time consuming, NB (Expts. 2, 3, 4, and 5) is recommended. A negative genetic association between TB and NB was indicated (Expt. 4). In Expts. 3 and 4, however, seedlings with high PDG and NB were also found in families where high CR genotypes with later budbreak time were used as parents, indicating that early TB as pre-selection criterion may exclude seedlings with increased budbreak.

Although the number of buds breaking on intact shoots does not distinguish between correlative factors on budbreak within and outside the seedlings, such as hormonal control, results from these experiments indicate that NB is a successful index. Variation between families in our material was detectable using the PDS and NB indices. Response to selection based on PDG indicates that visual selection can be a pre-selection criterion for increased budbreak, but the ordinal nature of the measurement scale of this index creates limitations for quantitative genetic analyses.

Controlled chilling can differ from field chilling in measurement and prediction of CR (Hauagge and Cummins, 1991a; Mahmood et al., 2000; Tehranifar et al., 1998). It was also shown that budbreak can be increased under controlled conditions, but up to a specific point, where further chilling can reduce budbreak (Halgryn et al., 2001; Mahmood et al., 2000). Selection at high $\mathrm{CU}$ is less practical than overwintering seedlings in suboptimal winter conditions (Hauagge and Cummins, 1991c; Oppenheimer and Slor, 1968). Our observations also indicate that the use of controlled chilling for pre-selection is unlikely to identify seedlings adaptable to suboptimal climatic conditions.

The use of cut shoots to investigate variation in CR shows some limitations. Previously, response to chilling of cut shoots was found to differ from whole trees (Mahmood et al., 2000; Wilson et al., 1975) and in some cases buds may not have completely entered dormancy before shoots were cut, thus delaying the process of budbreak (Halgryn et al., 2001). The optimum time to collect shoots is difficult to determine. Our experiment with cut shoots shows that results vary between years.

High temperatures gradually assume more control over bud development as trees approach completion of rest (Bailey and Hough, 1975; Brown, 1960; Kester et al., 1977). Bud development progresses only if chilling is supplemented with temperatures favorable to growth (Kriebel and Wang, 1962; Worrall and Mergen, 1967). Bud failure can occur because of temperatures not suitable for normal budbreak, leading to delayed and protracted budbreak (Cook et al., 1998; Hauagge and Cummins, 1991a; Mauget and Rageau, 1988). Seedlings may differ in their heat requirement or rapidity of response to favorable conditions after their CR was satisfied. Hence, the interaction of chilling and heat units to break dormancy can complicate the process of dormancy release (Billington and Pelham, 1991; Topp and Sherman, 2000) and selection for climatically adapted cultivars. The data presented in this paper are confounded with the variation of genotype-heat requirement. 
Seedling age can affect the length of bud dormancy (Hauagge and Cummins, 1991b) and possibly budbreak number. Buds from juvenile seedlings may be rated higher than those of a mature plant. The gains of early selection depend on age-age correlations (Rehfeldt, 1992) and, therefore, it remains to test whether the seedling response to selection for increased budbreak is carried over to an adult phase. Despite these complications, the NB of intact 1 -year-old shoots under natural conditions is recommended as pre-selection criterion for selection to local adaptability.

\section{Literature Cited}

Allan, P., A.P. George, R.J. Nissen, T.S. Rasmussen and M.J. Morley Bunker. 1993. Effects of paclobutrazol on phenological cycling of low-chill 'Flordaprince' peach in subtropical Australia. Sci. Hort. 53:73-84.

Bailey, C.H. and L.F. Hough. 1975. Apricots, p. 367-383. In: J. Janick and J.N. Moore (eds.). Advances in fruit breeding. Purdue Univ. Press, West Lafayette, Ind.

Billington, H.L. and J. Pelham. 1991. Genetic variation in the date of budburst in Scottish birch populations: Implications for climate change. Funct. Ecol. 5:401-409.

Bradshaw, H.D., Jr., and R.F. Stettler. 1995. Molecular genetics of growth and development in poplars. IV. Mapping QTLs with large effects on growth, form, and phenology traits in a forest tree. Genetics 139:963-973.

Brown, D.S. 1960. The relation of temperature to the growth of apricot flower buds. Proc. Amer. Soc. Hort. Sci. 75:138-147.

Chandler, W.H. 1960. Some studies of rest in apple trees. Proc. Amer. Soc. Hort. Sci. 76:1-10.

Cook, N.C. and G. Jacobs. 2000. Progression of apple (Malus $\times$ domestica Borkh.) bud dormancy in two mild winter climates. J. Hort. Sci. and Biotech. 75:233-236.

Cook, N.C., E. Rabe, J. Keulemans, and G. Jacobs. 1998. The expression of acrotony in deciduous fruit trees: A study of the apple rootstock M.9.
J. Amer. Soc. Hort. Sci. 123:30-34.

Denardi, F., L.F. Hough, and J.I. da S. Bonetti. 1988 Low chilling and disease resistance as main objective of apple breeding in Santa Catarina, Brazil. Acta Hort. 232:15-25.

Dennis, F.G., Jr. 1987. Two methods of studying rest:Temperature alteration and genetic analysis. HortScience 22:820-824.

Falconer,D.S. and T.F.C. Mackay, 1996. Introduction to quantitative genetics. 4th ed. Longman, New York.

Fuchigami, L.H. and M. Wisniewski. 1997. Quantifying bud dormancy: Physiological approaches. HortScience 32:618-622.

Halgryn, P.J., K.I. Theron and N.C. Cook, 2001. Genotypic response to chilling period of apple buds from two Western Cape localities. SA. J. Plant Soil 18:21-27.

Hauagge, R.H. and J.N. Cummins. 1991a. Seasonal variation in intensity of bud dormancy in apple cultivars and related Malus species. J. Amer. Soc. Hort. Sci. 116:107-115.

Hauagge, R.H. and J.N.Cummins. 1991b. Age, growing temperatures, and growth retardants influence induction and length of dormancy in Malus. $\mathrm{J}$. Amer. Soc. Hort. Sci. 116:116-120.

Hauagge, R.H. and J.N. Cummins. 1991c. Genetics of length of dormancy period in Malus vegetative buds. J. Amer. Soc. Hort. Sci. 116:121-126.

Herter, F.G., N.L. Fenardi, and J.C. Mauget. 1988. Dormancy development in apple trees in cultivars Gala, Golden and Fuji in Pelotas. Acta Hort. 232:109-115.

Howe, G.T, J. Davis, Z. Jeknic, T.H.H. Chen, B. Frewen, H.D. Bradshaw Jr., and P. Saruul. 1999. Physiological and genetic approaches to studying endodormancy-related traits in Populus. HortScience 34:1174-1184.

Kester, D.E., P. Raddi, and R. Assay. 1977. Correlations of chilling requirements for germination, blooming and leafing within and among seedling populations of almond. J. Amer. Soc. Hort. Sci. 102:145-148.

Kriebel, H.B. and C.W. Wang. 1962. The interaction between provenance and degree of chilling in budbreak of sugar maple. Silvae Genet. 11: 125-130.

Linsley-Noakes, G.C., M. Louw, and P. Allan. 1995.
Estimating daily positive Utah units using daily minimum and maximum temperatures. J. SA. Soc. Hort. Sci. 5:19-23

Mahmood, K., J.G. Carew, P. Hadley, and N.H. Battey. 2000. Chill unit models for the sweet cherry cvs. Stela, Sunburst and Summit. J. Hort. Sci. and Biotechnol. 75:602-606.

Mauget, J.C. and R. Rageau. 1988. Bud dormancy and adaptation of apple tree to mild winter climates. Acta Hort. 232:101-108.

Oppenheimer, C.H. and E. Slor. 1968. Breeding of apples for a subtropical climate. II. Analyses of two $\mathrm{F}_{2}$ and nine backcross families. Theor. and Appl. Genet. 38:97-102.

Rehfeldt, G.E. 1992. Early selection in Pinus pondorosa: Compromises between growth potential and growth rhythm in developing breeding strategies. Forest Sci. 38:661-677.

Richardson, E.A., S.D. Seeley, and D.R. Walker. 1974. A model for estimating the completion of rest for 'Redhaven' and 'Elberta' peach trees. HortScience 9:331-332.

SAS Institute Inc. 1996. The SAS system. Release 6.12. SAS Inst., Cary, N.C.

Shapiro, S.S. and M.B.Wilk. 1965. An analysis of variance test for normality (complete samples). Biometrika 52:591-611.

Snedecor, G.W. and W.G. Cochran. 1991. Statistical methods. 8th ed. Iowa State Univ. Press, Ames.

Tehranifar, A., P. Le Miérre, and N.H. Battey. 1998. The effect of chilling date, chilling duration and forcing temperature on vegetative growth and fruit production in the June bearing strawberry cultivar Elsanta. J. Hort. Sci. and Biotechnol. 73:453-460.

Topp, B.L. and W.B. Sherman. 2000. Breeding strategies for developing temperate fruits for the subtropics, with particular reference to Prunus. Acta Hort. 522:235-240.

Wilson, D., R.P. Jones, and J. Reeves. 1975. Selection for prolonged winter dormancy as a possible aid to improving yield stability in European plum (Prunus domestica L.). Euphytica 24: 815-819.

Worrall, J. and F. Mergen. 1967. Environmental and genetic control of dormancy in Picea $a b$ ies. Physiol. Plant. 20:733-745. 